\title{
DISSECTING ANEURYSM OF THE AORTA IN MOTHER AND CHILD
}

\author{
BY \\ G. J. GRIFFITHS, A. P. HAYHURST, AND RAYMOND WHITEHEAD
}

From the Department of Pathology, University of Manchester

Received March 15, 1951

Shennan's report on dissecting aneurysm of the aorta (1934) was based on 297 cases. Ten years later Schnitker and Bayer found that the total number of cases had risen to 580; of these, 141 (24\%) occurred before the age of 40 and these form the subject of their paper. Of the total 141, 92 were males and 49 females; in 24 of the females $(49 \%)$ the aneurysm occurred in association with pregnancy. Another point of interest emerging from this study is the occasional occurrence of dissecting aneurysms in childhood and adolescence: 31 cases -5 per cent of the total 580-occurred in the age range 1 to 20 years.

In this paper we report a further case associated with pregnancy and a case in a 14-year-old boy. The patients were mother and son and this fact adds special interest. It may be no more than coincidence that two such close relatives should die of the same uncommon disease; it suggests, however, the possibility of a hereditary predisposition to dissecting aneurysm and the need of investigating the family history in this disease.

\section{CASE 1}

The patient, aged 34, had always been regarded as delicate; she easily became tired and exhausted and found hills a great effort. She used to suffer from low backache, but never seems to have complained of pain in the mid-thoracic region. There were no other illnesses of note. She bore four children: the first was our Case 2; the second and third are alive and well; the fourth was one month premature and lived for only two weeks; the cause of death of this child is not known.

She did not get up after this last confinement, and on the sixth day she suddenly felt she was "sinking through the bed "; she did not complain of pain or any other symptoms. On the seventh day she experienced the same feeling, but on the eighth day she felt very much better and remained so for some 36 hours. On the ninth day she "felt herself going," became progressively more and more dyspnœic, and died.

At necropsy the body was thin and sallow; there were no external injuries. The heart showed fatty infiltration; the coronary arteries were patent. The aorta showed patches of atheroma, but the main lesion was a dissecting aneurysm involving the first three inches of the abdominal aorta. The abdominal cavity was full of blood clot. The liver and spleen were pale and friable, the stomach and intestines normal. The uterus showed normal involution and there was no sign of uterine infection. The brain was not examined. The anatomical diagnosis was ruptured dissecting aneurysm of the abdominal aorta and atheroma of the aorta. No tissue was taken for histological examination.

\section{CASE 2}

This patient, the first child.of the previous patient (Case 1) was 14 years old. There had been no difficulty in the confinement or puerperium and he was normally developed at birth. He was an able child and had won a scholarship at the age of 12. He found physical exertion exhausting and did not take part in the usual school games; he ran as little as possible. At the age of 11 he had an attack of pleurisy, and a few months before his death he had an upper respiratory infection, which kept him in bed for a week. 
At 6 p.m. on the day of his death, he was playing boisterously with his sister and in the process knocked 'his head on the wall; he did not complain unduly of this. At 10 p.m. he was playing with his brothers and sisters before going to bed. At 10.15 p.m. he sat down on the settee to take off his shoes; he had removed one and was in the act of removing the other when he complained of a sudden sharp pain in the chest. He immediately ran upstairs to his sister, who went for help at once. He then came downstairs and stood at the front door. He spat up a quantity of blood and became very frightened; he lay down on the settee and began to become faint.

On examination a few minutes later, he was almost pulseless, cold, pale, and sweating profusely. He was semi-comatose and in such obvious agony that it was impossible to examine him satisfactorily. Spontaneous pneumothorax was suspected; the boy was carried upstairs to his bed to await an ambulance, but he died before it arrived. When the body was removed after death it was obvious from the splash that the thorax was full of fluid.

At necropsy the skull was found to be healthy; the meninges were pale from loss of blood. The pericardium and heart were healthy and the cavities of the heart contracted. Both lungs were collapsed and the mediastinum contained an irregular hæmorrhagic mass about $13 \mathrm{~cm}$. in diameter which showed on its left side a rupture about $4 \mathrm{~cm}$. long. Blood had tracked downwards on the posterior mediastinum and clots were found behind the peritoneum. There was some free fluid in the lesser sac. The liver was pale, the spleen contracted and, on section, like soft putty. The other viscera were normal. The thoracic viscera were sent to the laboratory for further study.

The specimen was a blood-sodden mass consisting of the larynx, trachea, bronchi, and parts of the left lung and aorta. The aortic segment included most of the arch; when opened longitudinally it showed no lesion; when cut transversely it showed a dissecting aneurysm in the media extending over about two-thirds of the circumference of the aorta. The upper limit of the dissection could not be located with certainty and the lower limit was not included in the specimen.

For histological examination, pieces of dissected-and non-dissected aorta were fixed in 10 per cent formolsaline and sectioned transversely. The stains applied are shown in the accompanying table. Paraffin sections were used except for sudan IV, which required frozen sections. All the sections were examined under a polarizing microscope, as well as in the ordinary way.

Stains Applied to Aorta ANd Reaction of Mucoid Material in Media

\begin{tabular}{|c|c|c|c|}
\hline Stain & Reaction & Stain & Reaction \\
\hline 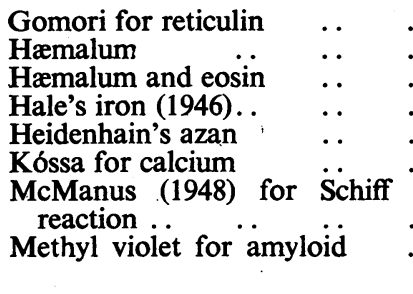 & $\begin{array}{l}\text { Negative } \\
\text { Bluish } \\
\text { Bluish } \\
\text { Green } \\
\text { Uncertain } \\
\text { Negative } \\
\text { Pink } \\
\text { Negative }\end{array}$ & 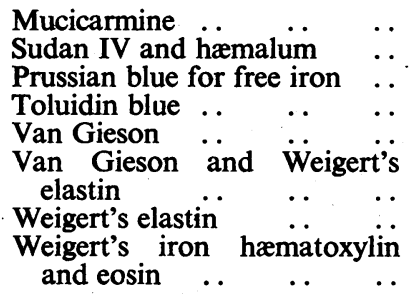 & $\begin{array}{l}\text { Negative } \\
\text { Negative for fat } \\
\text { Negative } \\
\text { Reddish-purple } \\
\text { Uncertain } \\
\text { Negative for elastin } \\
\text { Negative } \\
\text { Bluish }\end{array}$ \\
\hline
\end{tabular}

At the edges of the aneurysm, the split was at the junction of the outer third and inner two-thirds of the media (Fig. 1). The outer wall of the aneurysm tapered rapidly from the edges and most of it was extremely thin. Further splitting of the outer wall had occurred near one edge (Fig. 2). The aneurysm was lined by a thick irregular layer of blood clot showing no evidence of organization. The adventitia was obscured by hæmorrhage but the intima was normal. The composition of the media was the same in both the dissected and non-dissected pieces of aorta. Elastic tissue, reticular fibrous tissue (Fig. 3) and muscle were present, but the laminæ of these tissues were separated by mucoid material, which was most abundant in the inner half of the media (Fig. 4).

This mucoid material did not have the histological appearance of necrotic muscle or necrotic collagen. It was a homogeneous, afibrillar substance showing no birefringence with polarized light. It contained moderate numbers of small cysts or bubbles; these may well have been artefacts indicating its friable nature, since they were especially numerous along scratches produced accidentally during preparation of the sections. 


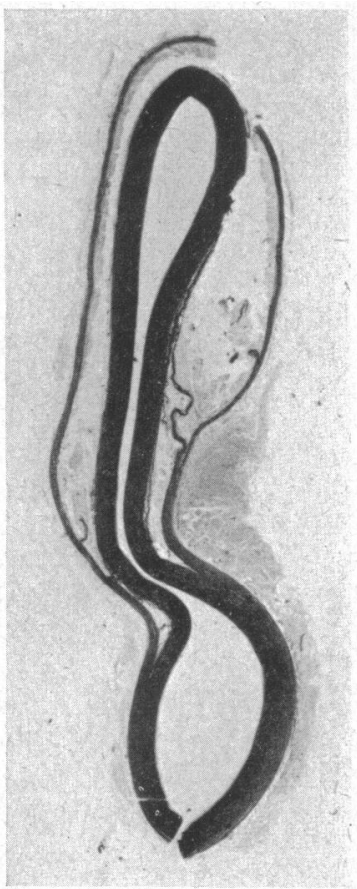

FIG. 1.-Case 2. Transverse section of aneurysm showing its very thin outer wall. The interruption in this wall (top of figure) and that in the unsplit part of the aorta (bottom of figure) represent incisions made for inspection. Weigert's elastin stain. $\left(\times 4 \frac{1}{2}\right.$.)

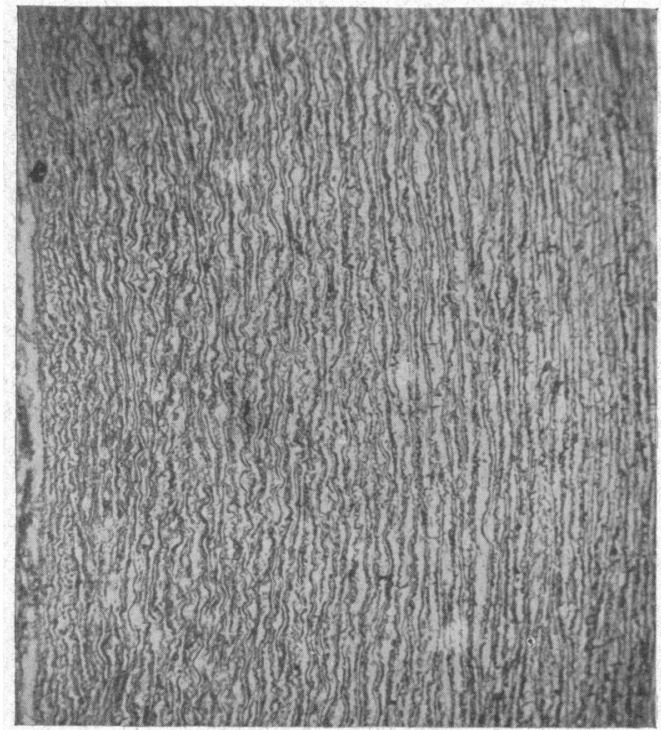

Fig. 3.-Case 2. Transverse section of unsplit part of aorta at level of aneurysm stained for reticulin by Gomori's method. Elastic tissue and mucoid material are unstained. ( $\times 100$.

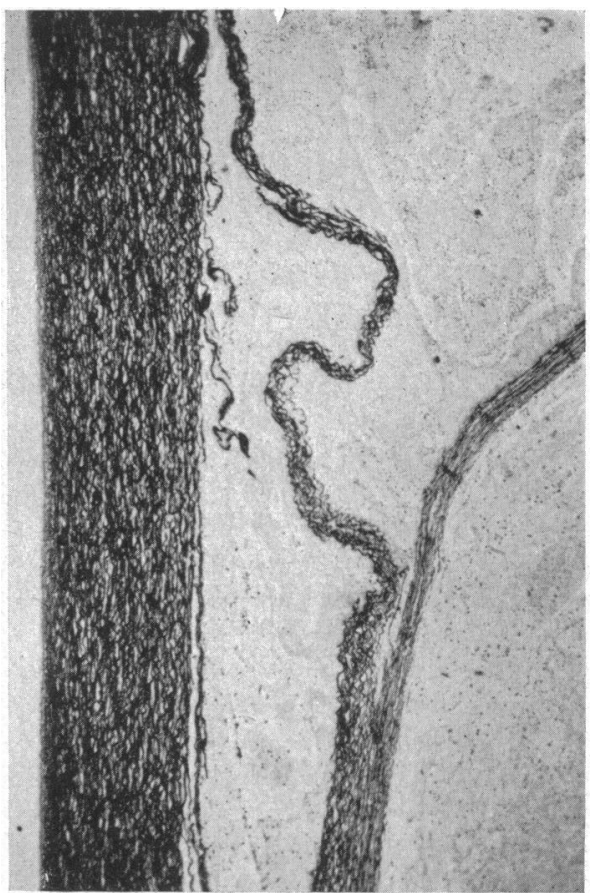

FIG. 2.-Case 2. From same section as Fig. 1, showing split in outer wall of aneurysm. The light grey granular appearance within and outside the aneurysm represents blood clot. $(\times 30$.

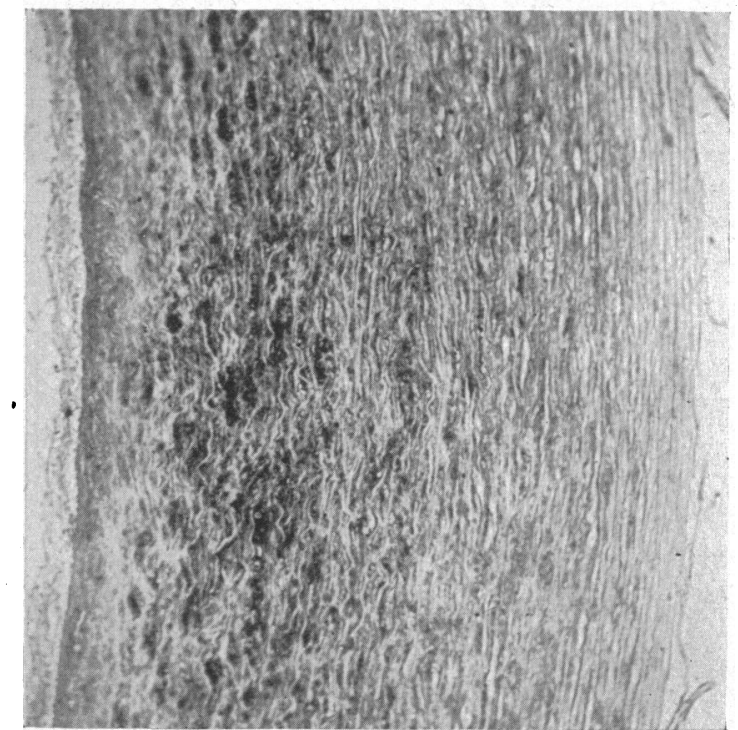

Fig. 4.-Case 2. Section near that shown in Fig. 3 showing dark mucoid material, most abundant in inner half of media (left half of figure). Hale's iron method. ( $\times 100$.) 
The staining properties of the mucoid material are shown in the table. The green colour after Hale's method suggests the presence of acid mucopolysaccharides; the negative result after mucicarmine-a common finding-does not exclude the presence of substances of this type. The reddish-purple after toluidin blue suggests the presence of high molecular esters of polysulphuric acid, and the pink colour after the McManus technique (an application of the Schiff periodic acid reaction) can also be taken as evidence that mucopolysaccharides were present.

\section{Discussion}

Clinical diagnosis. The clinical diagnosis of dissecting aneurysm is beset with difficulties. The patient may not survive a dissection long enough for special investigation, or may be too ill to tolerate even a normal clinical examination. If a diagnosis is made, it is not unlikely to be coronary disease, and this may well be registered as the cause of death (Gardner et al., 1939). Another probable diagnosis is that of an acute abdominal emergency, with laparotomy as a possible consequence.

Although the clinical picture of dissecting aneurysm is not constant, there is one characteristic symptom-namely a sudden attack of severe pain in the chest or abdomen (Holland and Bayley, 1940). No age is exempt; the youngest patient on record was 14 months old (Frei, quoted by Sailer, 1942), but medial lesions without dissection have been known to occur in a 12-day-old infant (Wolff, 1932); the oldest patient, noted by Shennan (1934), was nearly 100 years old.

Diagnosis at necropsy. If the patient comes to necropsy, the diagnosis is usually easy; in most cases there is a tear in the intima that should be obvious when the aorta is opened. In some cases, however, the intima is intact (Tyson, 1931; Mote and Carr, 1942) and the nature of the disease may then not be evident; hæmorrhage from a dissecting aneurysm that has ruptured through the adventitia may be attributed to some other source. It would therefore be a good practice to cut the aorta transversely after opening it longitudinally in all cases of sudden death without obvious cause, especially when there are signs of hæmorrhage in the thorax or abdomen.

Association with pregnancy. The association of dissecting aneurysm with pregnancy awaits explanation. Schnitker and Bayer (1944) found that of the 24 cases they considered, 6 occurred in the first six months, 14 in the last three months, 2 with labour pains, and 2 during the puerperium-one of them twelve days, the other three weeks post partum. Most of the cases thus occurred during the last three months of pregnancy and showed no special relation to labour. The dissection was therefore not attributable to the strain and blood-pressure changes associated with childbirth; a more likely factor was thought to be disturbed lipid metabolism, in particular the accumulation of cholesterol in the media. They recalled a similar association between dissecting aneurysm, post-operative hypothyroidism, and raised blood cholesterol. Another possible explanation is the softening of connective tissues that occurs in pregnancy, but whether the aorta is affected does not appear to be known.

Hereditary predisposition. The close relationship of our two patients suggests the possibility of a hereditary predisposition to dissecting aneurysm; both patients found physical exertion exhausting, which suggests that there may be a constitutional factor. The fact that the father and the four children of his first marriage are all healthy points to the second wife as the sole vector and it is regrettable that the cause of death of her premature child is not known. Our experience simply suggests that it would be worth while exploring the family history in cases of dissecting aneurysm.

Other possible atiological factors. Physical exertion has long been considered as a possible factor in the production of dissecting aneurysm, especially in young patients (Wasastjerna, 1903). Exertion per se, however, is clearly an insufficient explanation, as otherwise dissecting aneurysms would be much commoner than they are. Reich (1944) notes that Willius and Cragg found hypertension in 80 per cent of cases of dissecting aneurysm, but adds that of 283 hypertensives studied by Thomas and Garber only 2 had dissecting aneurysms; from the hypertensive's point of view, dissecting aneurysm is therefore not a serious risk.

AEtiological significance of medial changes. The most important ætiological factor is now thought to be pathological changes in the aortic media. According to Sailer (1942), five main types of medial change may be associated with dissecting aneurysms: (1) fatty degeneration, fragmentation or necrosis of elastic tissue (sometimes with mucoid change), (2) hyaline degeneration of connective tissue, (3) fatty degeneration and atrophy of muscle, (4) necrosis of muscle (sometimes with mucoid change), and (5) primary mucoid infiltration with cyst formation (commonest in the ascending part of the aortic arch), which is illustrated by our Case 2.

This classification extends the work of Gsell (1928) and Erdheim (1929; 1930), who described the main 
features of the medial change as patchy necrosis of muscle, mucoid degeneration with cyst formation, and repair of the media without signs of inflammation. Thus the pathological picture, which Erdheim (1930) finally designated medionecrosis aorte idiopathica cystica, is not well defined, and the inter-relations and relative importance of the various changes are not clear. Amromin et al. (1948), however, regarded this varied morphology as the expression of a single morbid process-namely medial ischæmia. In support of their opinion they described narrowing of the vasa vasorum in 7 of 12 aortas with dissecting aneurysm, whereas in 20 control aortas only 2 showed narrowing of these vessels without medial and intimal changes 'in the aorta.

The interpretation of the significance of these medial changes is made more difficult by the fairly common finding of similar changes in the absence of dissecting aneurysms. Our own observations throw no light on the questions whether mucoid change may initiate a dissecting aneurysm or facilitate the course of the effused blood. The occurrence of mucoid change is not peculiar to the aorta; it may be found, for example, in the renal artery in some cases of hypertension, in arteries showing calcification of the media, and in the stroma of parotid tumours. It therefore seems possible that aortic mucoid may be merely a local manifestation of a more general change occurring in connective tissue. Since the mucoid material seen in our Case 2 did not resemble necrotic muscle or necrotic collagen, the possibility that mucoid change may be reversible is worthy of consideration.

To facilitate the study of medial changes and their possible relation to dissecting aneurysm, the changes seen in individual cases should be specified exactly; medionecrosis is a comprehensive term covering a variety of changes, and to apply it, for example, to the mucoid change seen in our Case 2 would be inappropriate and misleading.

\section{SUMMARY}

Two cases of dissecting aneurysm of the aorta, one in a woman of 34 , nine days after childbirth, the other in her 14-year-old son, are described. The relationship of the patients suggests the possibility of a hereditary predisposition to this disease.

The mother's aorta was not examined histologically and only part of the aneurysm from the boy was available for study. No lesion that might have initiated the dissection was found. Mucoid change was present in the inner media, but the dissection lay in the outer media.

The association between dissecting aneurysms and pregnancy may be due to the softening of connective tissues that occurs in pregnancy, and further work is needed to determine whether the aorta is among the organs affected. Mucoid change in the aorta may be simply one among many manifestations of a type of change occurring in intercellular tissues in general. The possibility that the change may be reversible is worthy of examination.

Clinically, dissecting aneurysm is likely to be mistaken for coronary disease or an acute abdominal emergency, its most characteristic feature being a sudden attack of severe pain in the chest or abdomen.

We are indebted to Dr. John Ball for generous assistance, to Drs. A. Morgan Jones and F. A. Langley for advice on Case 2, and to Professor A. C. P. Campbell for criticism of the manuscript. Most of the technical work was done by Messrs. F. Ward and B. W. Figg and the photographs are by Mr. F. Ward.

\section{REFERENCES}

Amromin, G. D., Schlichter, J. G., and Solway, A. J. L. (1948). Arch. Path., 46, 380.

Erdheim, J. (1929). Arch, path. Anat., 273, 454.

- (1930). Ibid., 276, 187.

Gardner, E., Galbraith, A. J., and Hardwick, S. W. (1939). Lancet, 2, 1019.

Gsell, O. (1928). Arch. path. Anat., 270, 1.

Hale, C. W. (1946). Nature, 157, 802.

Holland, L. F., and Bayley, R. H. (1940). Amer. Heart J., 20, 223.

McManus, J. F. A. (1948). Stain Technol., 23, 99.

Mote, C. D., and Carr, J. L. (1942). Amer. Heart J., 24, 69.

Reich, N. E. (1944). Clinics, 3, 346.

Sailer, S. (1942). Arch. Path., 33, 704.

Schnitker, M. A., and Bayer, C. A. (1944). Ann. intern. Med., 20, 486.

Shennan, T. (1934). Med. Res. Counc. Spec. Rep. Ser. No. 193.

Tyson, M. D. (1931). Amer. J. Path., 7, 581.

Wasastjerna, E. (1903). Z. klin. med., 49, 405.

Wolff, K. (1932). Arch. path. Anat., 285, 369. 